\title{
A METHOD FOR PREVENTION OF CARDIOVASCULAR REACTIONS TO LARYNGOSCOPY AND INTUBATION
}

\author{
Mounir Abou-Madi, Hugo Keszler, and Odile Yacoub
}

\section{INTRODUCTION}

THE FREQUent OCCURRENCE of cardiovascular reactions to laryngoscopy and tracheal intubation has attracted the attention of anaesthetists for more than twenty years. $^{1-12}$ The reason for this is the occasional report of sudden death following immediately on intubation ${ }^{8}$ and increasing awareness that the common appearance of tachycardia, hypertension and arrhythmia after this routine procedure of modern anaesthesia, may be potentially dangerous. This is especially true in hypertensive patients ${ }^{10-12}$ and in patients with coronary or cerebral vascular insufficiency. ${ }^{10,13}$ Preventive measures recommended include deep anaesthesia, ${ }^{1,10}$ intravenous procaine, ${ }^{2}$ beta blockers ${ }^{12}$ and topical anaesthesia. ${ }^{5}$ All these measures are only partially effective and, moreover, may have undesirable side effects.

We believe that effective topical anaesthesia of pharynx, larynx and trachea in combination with avoidance of excessive pressure of the laryngoscope blade should be successful in preventing cardiovascular reactions. Since it has been shown that laryngoscopy and spraying alone will often cause marked cardiovascular disturbances even before intubation is performed, it was our aim to find a method of topical anaesthesia that would be highly effective and which could be applied before general anaesthesia without being unpleasant or time-consuming. Aerosol anaesthesia is a method that has been rather widely used for bronchoscopy and bronchography. ${ }^{14-16}$ It was the purpose of this study to find out whether aerosol anaesthesia of the upper airway could offer a practical solution to our problem.

\section{Clinical Material and Methods}

The electrocardiographic and blood pressure responses during laryngoscopy and intubation were studied in 20 patients. The patients were divided into two groups: ten served as control and ten were pre-treated. Ages varied between 46 and 76 years. Treatments were alternated as much as possible and patients were paired according to age, weight, associated diseases and surgical pathology. Details of patients and pairing are shown in Tables I and II. Patients were examined on the day preceding the study. Their consent was obtained after full explanation of the purpose of the study. A standard premedication of pentobarbitone $2 \mathrm{mg} / \mathrm{kg}$ body weight was given intramuscularly $1 \%$ hours before the operation.

\section{Preparation of Patients}

Patients were brought to the anaesthetic room mildly sedated. A 20-gauge

From the Department of Anaesthesia, Queen Mary Veterans' Hospiral and McGill University, Montreal, P.Q.

Canad. Anaesth. Soc. J., vol. 22, no. 3, May 1975 


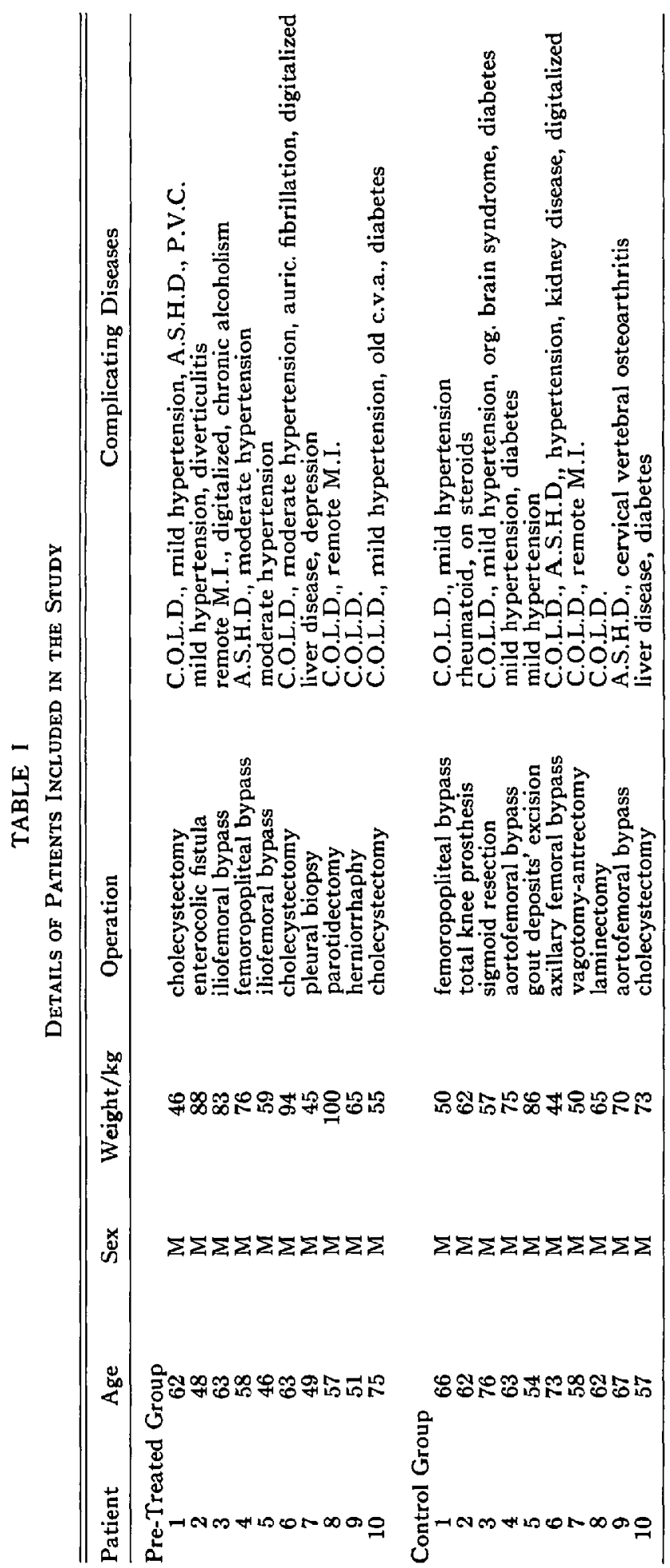


TABLE 2

PaIRING

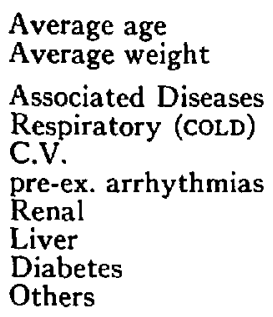

\begin{tabular}{llc}
\hline & \multicolumn{2}{c}{ Pre-Treated with Control } \\
\cline { 2 - 3 } & $\mathbf{1}$ & 1 \\
& 2 & 5 \\
& 3 & 6 \\
& 4 & 9 \\
& 5 & 4 \\
& 6 & 7 \\
& 7 & 2 \\
& 8 & 8 \\
Average age & 9 & 3 \\
Average weight & 10 & Control \\
Associated Diseases & & 63.8 years \\
Respiratory (cold) & Pre-Treated & $63.2 \mathrm{Kg}$ \\
C.V. & 57.2 years & \\
pre-ex. arrhythmias & 71.1 Kg & $60 \%$ \\
Renal & & $70 \%$ \\
Liver & $50 \%$ & $10 \%$ \\
Diabetes & $80 \%$ & $10 \%$ \\
Others & $20 \%$ & $10 \%$ \\
\cline { 2 - 3 } & $10 \%$ & $30 \%$ \\
& $10 \%$ & $20 \%$
\end{tabular}

Argyle catheter was inserted percutaneously into the left radial artery under 1 per cent procaine analgesia. An 18-gauge catheter was used to start an intravenous infusion of 5 per cent Dextrose-in-water. Standard electrocardiographic limb leads were applied.

A General Electric Surgical Monitor was used to display and simultaneously to record changes in blood pressure and electrocardiographic tracings. Blood gases were analyzed on an I.L. 313 analyzer and lidocaine levels were determined by gas chromatography in the ASTRA Laboratories, using the method described by Edhorn. ${ }^{17}$ The study was divided into eight periods or stages.

\section{Pre-Treated Group}

\section{Stage I. Preoperative Observation Period}

Patients were laid supine on the operating table. After three minutes, blood pressure and electrocardiogram were recorded for one minute and arterial blood drawn for gases, serum potassium and lidocaine levels.

\section{Stage II. The Aerosol}

Patients were allowed to inhale in the sitting position $6-8 \mathrm{ml}$ of a mixture consisting of 13 of 2 per cent viscous lidocaine and $\%$ of 4 per cent aqueous lidocaine. The addition of viscous lidocaine served the purpose of increasing the droplet size. Although lidocaine jelly contains practically the same components, we cannot recommend the general use of viscous lidocaine for inhalation until specific studies have been done to confirm the safety of this form of application. A modified Bird nebulizer was used to ensure maximum droplet deposition along the upper airways 
(Figures 1 and 2 ). It is believed that at least $2 \mathrm{ml}$ of the mist were lost around the patient's mouth during expiration and breath holding. At the end of the treatment, the oropharyngeal mucosa was stimulated. In most patients there was no reaction and many of them complained of hoarseness.

\section{Stage III. Post-Aerosol Observation Period}

Patients were laid supine for three minutes. At the end of the period arterial blood was drawn for determination of blood gases, serum potassium and lidocaine levels; blood pressure and electrocardiogram were recorded for one minute.

\section{Stage IV. Induction of Anaesthesia}

Thiopentone sodium $4 \mathrm{mg} / \mathrm{kg}$ body weight were injected and anaesthesia continued with nitrous oxide-oxygen 7:3 liters and halothane 0.5 per cent to 1 per cent for 5 to 10 minutes.

\section{Stage V. Steady State}

The steady state was defined as the stage of stabilization of vital signs under nitrous oxide-oxygen-halothane anaesthesia, with the patient breathing spontaneously and assisted when necessary to ensure adequate ventilation. During this period a two-minute tracing was taken and blood drawn for gases and serum potassium.

\section{Stage VI. Laryngoscopy}

Recordings of blood pressure and electrocardiogram were started and continued almost to the end of the following stage. Succinylcholine $1 \mathrm{mg} / \mathrm{kg}$ body weight was injected. Following fasciculations and ventilation, laryngoscopy was per-
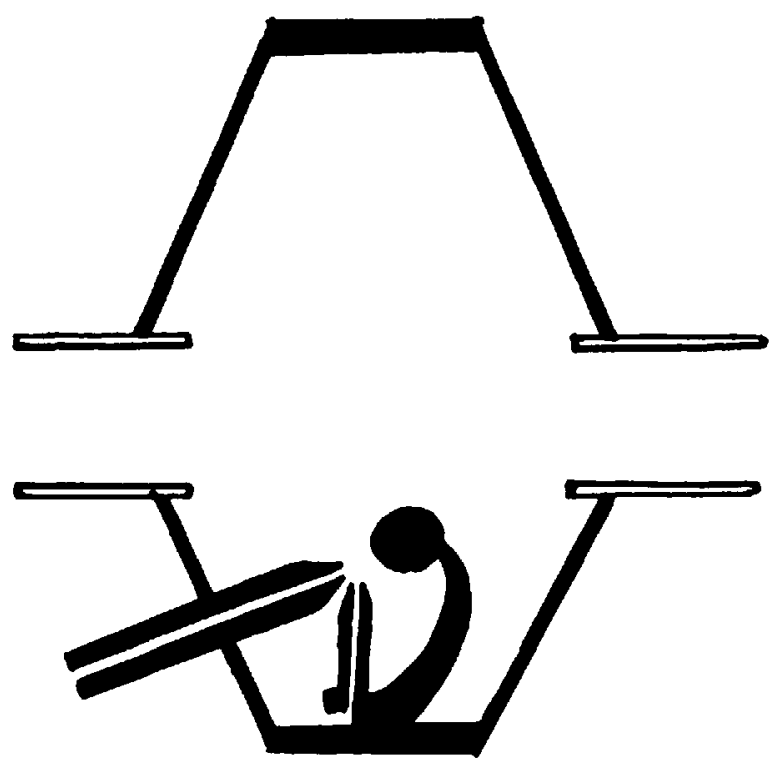

Figure 1. Schematic representation of a Bird nebulizer. 


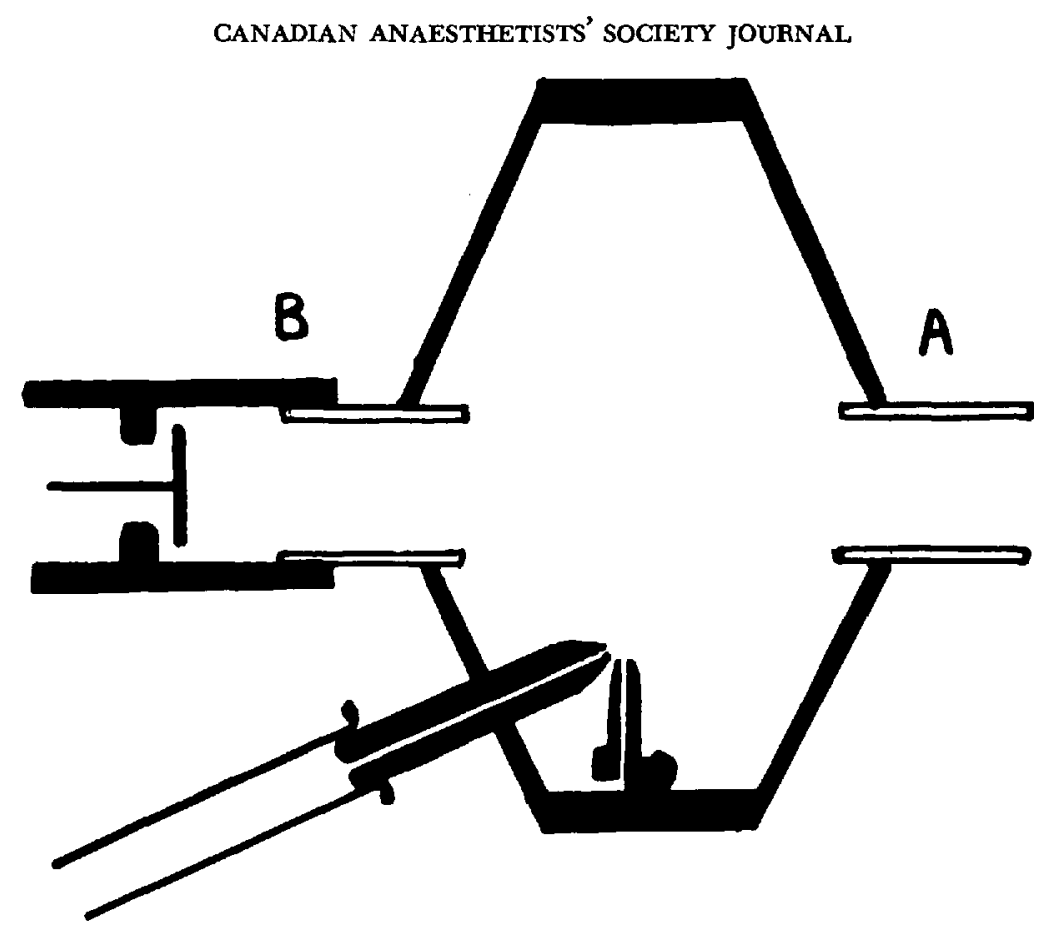

Figure 2. Schematic representation of the modified Bird nebulizer. Note the removal of the ball baffle to obtain coarser droplets, the addition of a one-way valve to allow for sufficient inspiratory flow and prevent loss of the mist from site $B$.

A six-litre oxygen flow was used to nebulize the lidocaine mixture.

formed, the cords visualized and four "squirts" of saline sprayed onto the larynx and between the cords.

\section{Stage VII. Intubation}

Intubation was performed using a tube of adequate size (usually $9 \mathrm{~mm}$. or 9.5 mm. I.D.), lubricated with a bland agent (Lubafax). With the lungs ventilated manually, the cuff was inflated after 20 seconds; blood pressure and electrocardiogram tracings were continued for two minutes. Blood gases, serum potassium and lidocaine levels were determined again at the end of this period. The patient was kept on the same anaesthetic concentration in stages V., VI. and VII.

\section{Stage VIII. Final Observation Period}

With the patients breathing spontaneously, a one-minute tracing was recorded and a final sample of blood drawn for gases, serum potassium and lidocaine levels, 5 to 10 minutes after intubation. The over-all study period lasted 30 to 45 minutes.

\section{Control Group}

In the patients of this group the same procedure was followed except that:

(1) Saline instead of lidocaine was nebulized in Stage II.

(2) Ten per cent lidocaine in Freon ("Xylocaine endotracheal aerosol Astra") was nebulized instead of saline, immediately prior to intubation. 


\section{Statistical Analysis}

Changes in blood pressure and pulse rate were analyzed statistically, employing Student's t-test for paired groups. Analysis was performed for changes within each group.

Three stages were used, viz. (1) steady state, (2) post-laryngoscopy and (3) one minute after intubation.

\section{RESULTS}

\section{Changes in Blood Pressure and Pulse Rate}

Details of mean changes in blood pressure and pulse rate in the pre-treated and control groups were as shown in Tables III and IV and Figures 3 and 4. The mean percentage changes as compared to the steady state were as shown in Table $\mathrm{V}$ and Figures 5 and 6. It should be noted that the maximal rise in blood pressure and pulse rate in both groups occurred one minute after intubation and that blood pressure fluctuations in the pre-treated group were much smaller and less abrupt than in the control group.

TABLE III

Mean Changes in Blood Pressure and Pulse-Rate

\begin{tabular}{|c|c|c|c|}
\hline \multirow[b]{2}{*}{ Blood Pressure } & \multicolumn{2}{|c|}{ Pre-Treated Group } & \multirow{2}{*}{$\begin{array}{c}1 \text { minute } \\
\text { post-intubation }\end{array}$} \\
\hline & Steady State & Laryngoscopy & \\
\hline $\begin{array}{l}\text { Mean } \\
\text { S.D. } \\
\text { S.E.M. }\end{array}$ & $\begin{array}{l}116 / 67 \\
\pm 19.01 / \pm 8.31 \\
\pm 6.01 / \pm 2.63\end{array}$ & $\begin{array}{l}114 / 69 \\
\pm 21.06 / \pm 13.99 \\
\pm 6.666 / \pm 4.42\end{array}$ & $\begin{array}{l}128 / 78 \\
\pm 20.69 / \pm 10.86 \\
\pm 6.54 / \pm 3.43\end{array}$ \\
\hline Pulse Rate & Steady State & Laryngoscopy & $\begin{array}{c}1 \text { minute } \\
\text { post-intubation }\end{array}$ \\
\hline $\begin{array}{l}\text { Mean } \\
\text { S.D. } \\
\text { S.E.M. }\end{array}$ & $\begin{array}{l}77 \\
\pm 12.13 \\
\pm 3.83\end{array}$ & $\begin{array}{l}79 \\
\pm 13.04 \\
\pm 4.12\end{array}$ & $\begin{array}{l}90 \\
\pm 12.07 \\
\pm 3.82\end{array}$ \\
\hline
\end{tabular}

TABLE IV

Mean Changes in Blood Pressure and Pulse-Rate

\begin{tabular}{llll}
\hline & & \multicolumn{2}{c}{ Control Group } \\
Blood Pressure & Steady State & Laryngoscopy & $\begin{array}{c}1 \text { minute } \\
\text { post-intubation }\end{array}$ \\
\hline Mean & $107 / 56$ & $138 / 74$ & $167 / 93$ \\
S.D. & $\pm 24.68 / \pm 14.62$ & $\pm 28.79 / \pm 18.97$ & $\pm 29.04 / \pm 15.08$ \\
S.E.M. & $\pm 7.8 / \pm 4.62$ & $\pm 9.1 / \pm 6.0$ & $\pm 9.18 / \pm 4.77$ \\
\hline & & & 1 minute \\
Pulse Rate & Steady State & Laryngoscopy & post-intubation \\
\hline Mean & 72 & 81 & 100 \\
S.D. & \pm 8.56 & \pm 10.92 & \pm 10.89 \\
S.E.M. & \pm 2.71 & \pm 3.45 & \pm 3.44 \\
\hline
\end{tabular}




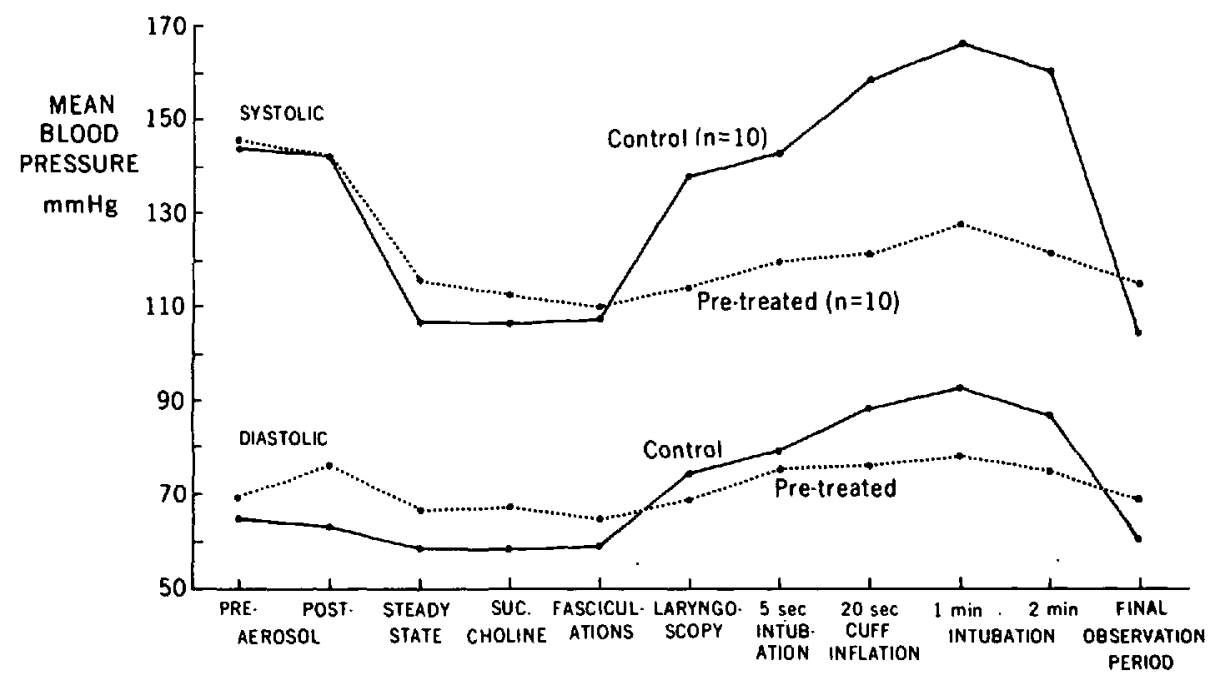

Figure 3. Mean blood pressure changes in control and pre-treated groups.

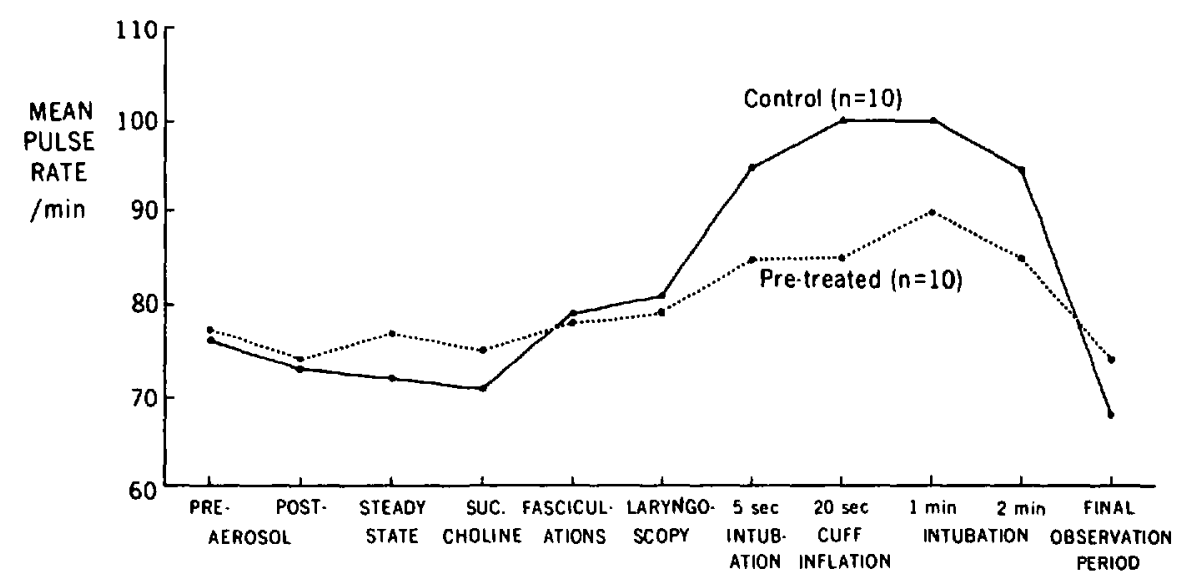

FIGURE 4. Mean pulse rate changes in control and pre-treated groups.

\section{INCIDENCE OF ARRHYTHMIAS}

\section{Pre-Treated Group}

There were no new arrhythmias or electrocardiographic changes except that patient No. 4 developed multiple supra-ventricular ectopic beats following the injection of succinylcholine. The arrhythmia stopped five seconds after tracheal intubation.

\section{Control Group}

The incidence of serious new arrhythmias and electrocardiographic changes was 40 per cent. These included atrio-ventricular heart block, bigeminy and ST segment 


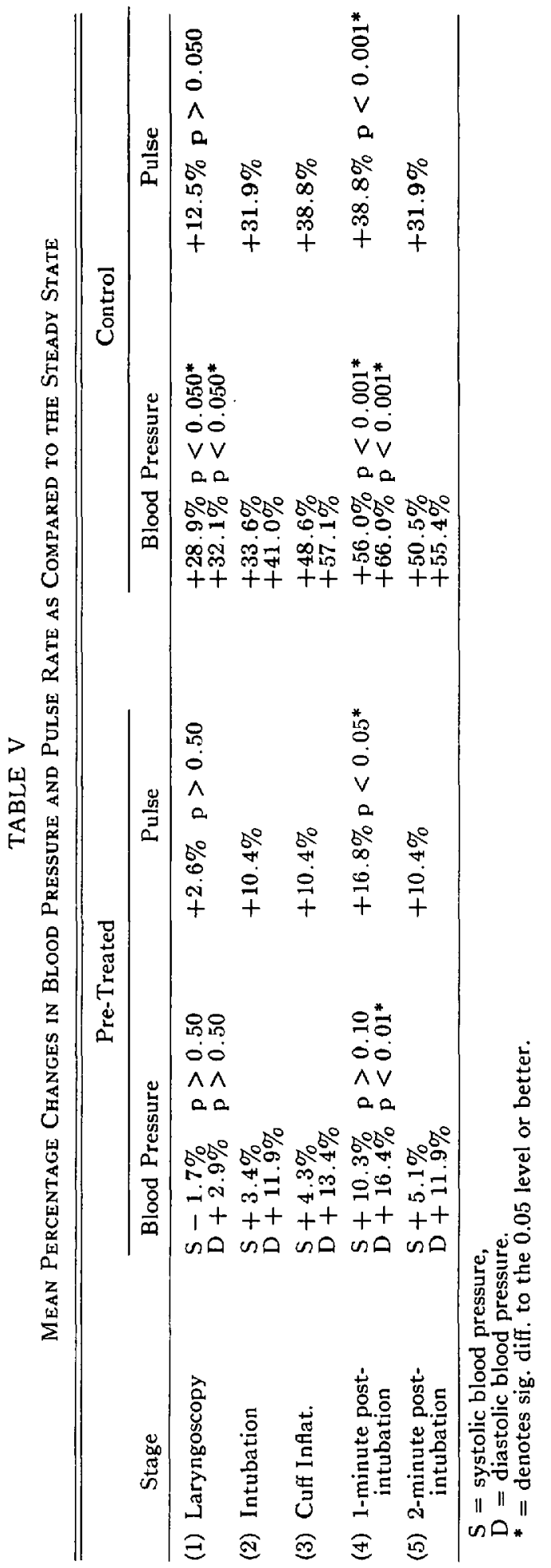



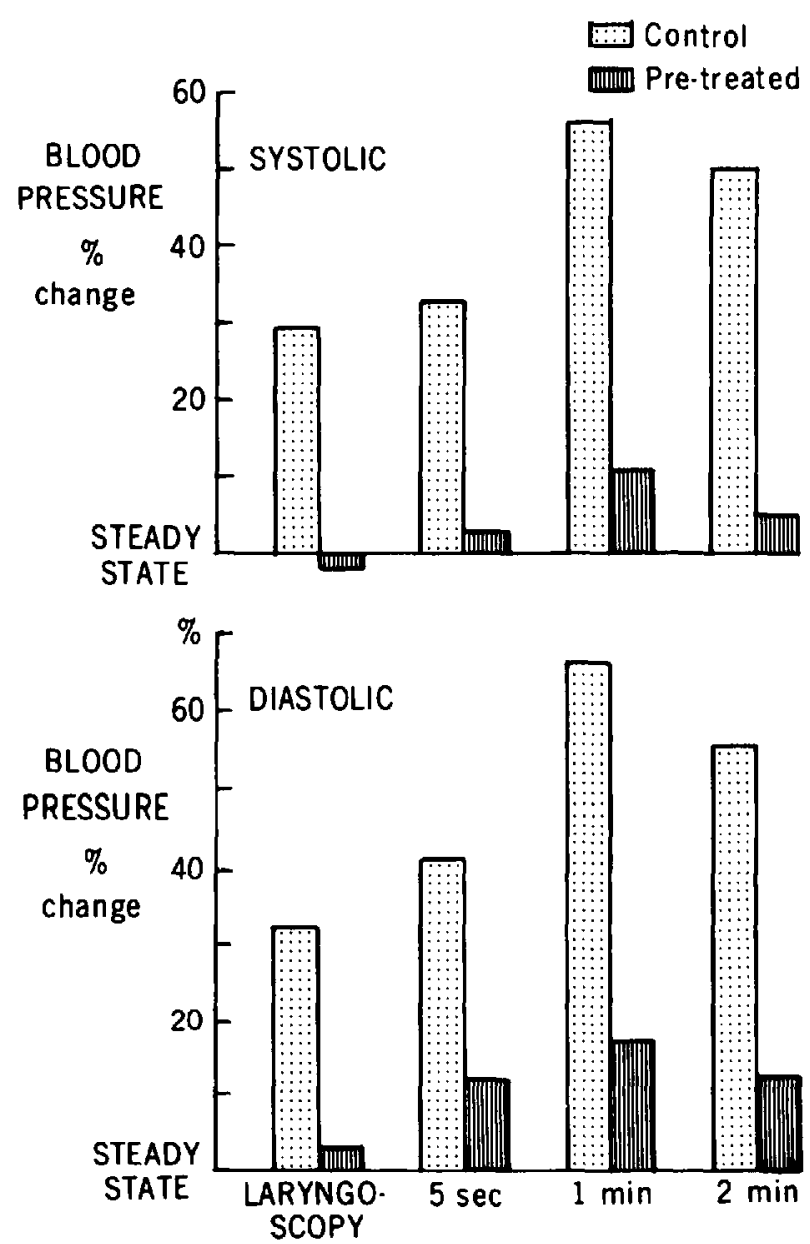

Figure 5. Blood pressure changes expressed in percentages in control and pre-treated groups during laryngoscopy; five seconds, one minute and two minutes post-intubation.

depression. These were observed during laryngoscopy and intubation in 20 per cent of the patients while in the remaining 20 per cent they followed one to two minutes later.

In patients No. 1 and No. 6 the arrhythmias continued into the final observation period.

The incidence of arrhythmias was highest in patients who had suffered the most acute rise in blood pressure (patients \#6 and \#7). Blood pressure fluctuations and electrocardiographic abnormalities were most prominent in patients with preexisting hypertension and arteriosclerotic heart disease (patients 1, 3, 4, 5, 6, 7 and 9 ).

\section{Lidocaine BLOOD LEVELS}

\section{Pre-Treated Group}

The average lidocaine blood level in this group, following nebulization was 1.2 


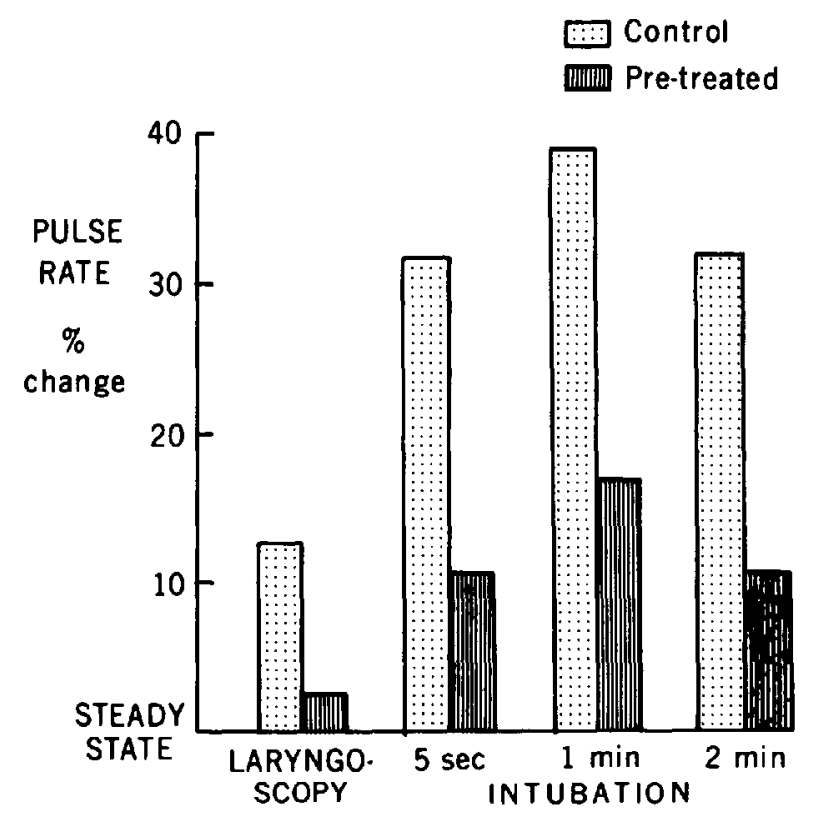

Figune 6. Pulse rate changes expressed in percentage in control and pre-treated groups.

microgram per $\mathrm{ml}$, two minutes after intubation it was 1.4 microgram per $\mathrm{ml}$ and at the end of the study it was 1.2 microgram per $\mathrm{ml}$.

\section{Control Group}

The average blood level two minutes after intubation was 0.4 microgram per $\mathrm{ml}$ and at the end of the study it was 0.3 microgram per $\mathrm{ml}$.

\section{Blood Gases and Serum Potassium}

Blood gases and serum potassium did not change significantly in either group except for the $\mathrm{Pa}_{\mathrm{O}_{2 .}}$ because $\mathrm{F}_{\mathrm{O}_{2.2}}$ had to be increased in some of the patients.

\section{Discussion}

Our objective was to find a simple and safe method for diminishing the incidence and severity of cardiovascular reactions to laryngoscopy and tracheal intubation.

Previous reports had shown that the laryngoscopy plays a larger part than the intubation in causing these cardiovascular reactions. . $^{5.6,11}$ Therefore, it would appear that the airway must be made analgesic before the laryngoscope is introduced. Pressure by the laryngoscope blade on the deeper structures and not only on the mucous membrane is responsible for these reactions. ${ }^{5.6}$ We omitted analgesic pre-medication to facilitate interpretation of our results. Atropine was also omitted, although only very large doses seem to have a preventive effect. ${ }^{1,5}$ There is reason to believe, however, that the drying effect of atropine might have made the aerosol more effective. ${ }^{16.18}$ 
Many methods of preventing cardiovascular reactions to tracheal intubation have been tried in the past and although topical anaesthesia was never convincingly shown to be effective, to our knowledge this is the only method employed routinely today. However, the common practice of spraying the larynx and trachea during laryngoscopy immediately before intubation must obviously be useless, not only in view of what has been said above ${ }^{5.6}$ but also because it takes at least one minute for the topical anaesthetic to become effective. ${ }^{18}$ Deep anaesthesia has some protective effect ${ }^{1.10}$ but is obviously undesirable for other reasons. Intravenous procaine one to five minutes before intubation has been shown to diminish the incidence of electrocardiographic changes after intubation to less than half. ${ }^{2}$ Furthermore, Bromage and Robson, ${ }^{10}$ studying blood levels of lidocaine after various methods of administration, endorsed the widely held impression that systemic absorption of lidocaine obtunds laryngeal reflexes. Steinhaus and Gaskin ${ }^{20}$ showed that intravenous lidocaine in a dose similar to that inhaled by our patients, is very effective in suppressing the cough reflex. There is evidence that after spraying $3 \mathrm{mg} / \mathrm{kg}$ body weight into the larynx and trachea ${ }^{21,22}$ blood lidocaine levels often approach those found to be effective in controlling premature ventricular contractions. ${ }^{23}$ For all these reasons we believe that the value of applying lidocaine topically to the upper airway might in part be due to its systemic effect. Our results show:

(1) Topical anaesthesia applied immediately before intubation is ineffective in preventing marked cardiovascular reactions to laryngoscopy and intubation.

(2) With the inhalation method used in this study protection was highly significant during laryngoscopy but less convincing, although still significant, after intubation, probably because topical anaesthesia of the trachea was incomplete.

(3) Systemic absorption of lidocaine probably accounts in part for the absence of arrhythmias in the pre-treated group. The average blood level was 1.4 microgram $/ \mathrm{ml}$ during intubation. The effective level for treating premature ventricular contractions is 2 to 5 micrograms $/ \mathrm{ml} .^{23}$ However, 5 microgram $/ \mathrm{ml}$ already approaches toxic levels. The highest blood level in our patients was 2.3 micrograms $/ \mathrm{ml}$.

(4) The incidence of post-intubation arrhythmias and hypertension is particularly marked in patients in whom these reactions could lead to serious complications i.e. in patients with hypertension and arteriosclerotic heart diseases.

(5) The results of blood gas analyses and serum potassium levels exclude the possibility that cardiovascular reactions could have been secondary to significant changes in ventilation or to excessive potassium levels after succinylcholine.

In connnection with these studies one must mention the extensive and thorough studies by Prys-Roberts and his group. ${ }^{11,12}$ During laryngoscopy and intubation in hypertensive patients they noticed excessive swings in blood pressure accompanied by electrocardiographic evidence of prolonged ischaemia in some. ${ }^{11}$ Deep anaesthesia would be undesirable in these patients because of the associated hypotension and myocardial ischaemia. In view of extensive circumstantial evidence that cardiovascular reactions after stimulation of the upper respiratory tract are mediated by increased sympathetic nervous activity $1, \mathbf{4}, 10,11$ and the supporting 
evidence from detailed studies in cats, ${ }^{24}$ they started using beta-blockers before tracheal suction of patients affected with tetanus. ${ }^{25}$ Encouraged by the results, they have used beta-blockers for the prevention of cardiovascular reactions to laryngoscopy and intubation. The method proved very effective ${ }^{12}$ and the results were very similar to those obtained in our pre-treated group. However, quite apart from widespread opposition to anaesthetizing patients for elective operations while they are under treatment with beta-blockers, practolol, the drug used by Prys-Roberts, is not available in North America and cannot simply be replaced by propranolol, since the peripheral $\left(\beta_{2}\right)$ effect of practolol on the arterioles is five times weaker than that of propranolol.

We believe that inhalation of a lidocaine aerosol is a safe, simple, effective and generally acceptable method. Obvious limitations are small children, unco-operative patients, patients sensitive to lidocaine and patients in whom there is a danger of aspiration due to regurgitation or vomiting. Lack of time is yet one more limitation. Our method is still in the experimental stage and we are well aware that the time factor must be controlled if it is to become generally accepted. We are now attempting to develop such a method. In the meantime, we have abandoned the routine use of a spray immediately before intubation, as it can obviously serve no useful purpose. In a small proportion of patients in whom we are anxious to avoid cardiovascular reactions, we use the inhalation method which we have described here.

\section{ACKNOWLEDGMENTS}

Our thanks are due to Doctor Fynes and Mr. Edhorn of ASTRA Pharmaceuticals, Toronto, Canada, for determining the lidocaine levels in our samples and to Miss T. Humphrey as well as other laboratory technicians at the Queen Mary Veterans' Hospital, Montreal, for analysing blood gases and estimating serum potassium levels in our patients.

\section{SUMMARY}

A technique of nebulizing lidocaine in the upper airways was developed and its effectiveness in preventing cardiovascular responses to laryngoscopy and intubation was documented. In ten pre-treated patients the average percentage-rise in systolic blood pressure was 10.3 per cent and there were no arrhythmias. The pulse rate increased by 16.8 per cent. In ten control patients, the systolic blood pressure increased by 56 per cent and the incidence of arrhythmias was 40 per cent. The pulse rate increased by 38.8 per cent. The significance and application of these results is discussed and compared to other available methods. The opinion is expressed that the effect of the aerosol, especially as it relates to the suppression of arrhythmias, is partly due to systemic absorption of lidocaine.

\section{RÉSUMÉ}

Nous avons procédé à l'étude de l'abolition du réflexe cardio-vasculaire lors de la laryngoscopie et de l'intubation à l'aide d'une technique d'inhalation d'un aérosol de lidocaine avant l'induction de l'anaesthésie. 
Dans les dix cas du groupe traitó l'augmentation de la tension artérielle pendant l'intubation, par rapport à l'état stable antérieur fut de 10.3 pour cent pour la pression systolique et de 16.4 pour cent pour la diastolique. L'augmentation du pouls fut de 16.8 pour cent et on n'observe pas d'arythmie.

Dans dix autres cas, servant de contrôle, nous avons pratiqué la technique habituellement utilisée, à savoir la vaporisation de lidocaine à 10 pour cent immédiatement avant l'intubation. Les resultats furent les suivants : augmentation de la tension artérielle de 56 pour cent pour la systolique, 66 pour cent pour la diastolique, augmentation du pouls de 38.8 pour cent et incidence d'arythmie de 40 pour cent.

Cette technique d'aérosol de lidocaine pré-opératoire s'est averée facile et efficace, pouvant être administrée par le patient lui-même, et est en definitive supérieure à la méthode de routine pre-intubation.

Il faut noter que l'absorption systemique de la lidocaine a pu contribuer à la stabilité cardio-vasculaire et à l'absence d'arythmie.

Notre discussion porte sur les resultats, et compare notre méthode à d'autres déjà publiées.

\section{REFERENCES}

1. Burstein, C.L., Lo Pinto, F.J., \& Newman, W. Electrocardiographic studies during endotracheal intubation. I. Effects during usual routine technics. Anesthesiology 11: 224 (1950).

2. Burstein, C.L., Woloshin, G., \& Newman, W. Electrocardiographic studies during endotracheal intubation. II. Effects during general anaesthesia and intravenous procaine. Anesthesiology 11: 299 (1950).

3. Noble, M.J. \& Derrick, W.S. Changes in electrocardiogram during endotracheal intubation and induction of anaesthesia. Canad. Anaesthetists' Society Journal 6:276 (1959).

4. DeVault, M., Greifenstein, F.E., \& Harris Jr., L.C. Circulatory responses to endotracheal intubation in light general anaesthesia - the effect of atropine and phentolamine. Anesthesiology $21: 360$ (1960).

5. WxcoFF, C.C. Endotracheal intubation: effects on blood pressure and pulse rate. Anesthesiology $21: 153$ (1960).

6. Takeshima, K., Noda K., \& Higaki, M. Cardiovascular response to rapid anaesthesia induction and endotracheal intubation. Anesth. Analg. Curr. Res. 43: 201 (1964).

7. Sagarminaga, J. \& Wynands, J.E. Atropine and the electrical activity of the heart during induction of anaesthesia in children. Canad. Anaesthetists' Society Journal 10:328 (1963).

8 Gises, J.M. The effects of endotracheal intubation on cardiac rate and rhythm. N.Z. Med. J. 66: 465 ( 1967 ).

9. Dotrori, O., Lof, B. Ax:son \& YGGe, H. Heart rate and arterial blood pressure during different forms of induction of anaesthesia in patients with mitral stenosis and constrictive pericarditis. Brit. J. of Anaesthesia 42: 849 (1970).

10. Forbes, A.M. \& DAll.y, F.G. Acute hypertension during induction of anaesthesia and endotracheal intubation in normotensive man. Brit. J. of Anaesthesia 42: 618 (1970).

11. Prys-Roberts, C., Greene, L.T., Meloche, R., \& Foex, P. Studies of anaesthesia in relation to hypertension. II. Haemodynamic consequences of induction and endotracheal intubation. Brit. J. Anaesth. 43: 531 (1971).

12. Prys-Roberts, C., Foex, P., Biro, G.P., \& Rogerts, J.G. Studies of Anaesthesia in relation to hypertension. V: Adrenergic beta-receptor blockade. Brit. J. Anaesth. 45: 671 (1973).

13. Dalton, B. \& Guiney, T., et al. Myocardial ischemia from tachycardia and hypertension in coronary heart disease - patients undergoing anaesthesia. Ann. Mtg. American Sac. of Anesthesiologists, Boston, 1972, pp. 201-202.

14. Molnar, W. \& Prior, J.A. Anaesthesia for bronchography utilizing intermittent positive pressure breathing apparatus. Am. J. of Roentgenology, Rad. Ther. and Nucl. Med. 87: 836 (1962). 
15. Tomasherski, J.F., Nelson, S.W., \& Christoforidis, A.J. Oropharyngeal and tracheobronchial aerosol anaesthesia. Dis. of the Chest. $42: 181$ (1962).

16. Nelson, S.W. \& Christoformis, A.J. An automatic inhalation-actuated aerosol anaesthesia unit: a new method of applying topical anaesthesia to the oropharynx and tracheobronchial tree. Radiology 82: 226 (1964).

17. Edhorn, G.A. Determination of lidocaine in whole blood by gas chromatography. Canad. Anaesthetists' Soc. J. 18: 189 (1971).

18. Dripps, R.D., Eckenhoff, J.E., \& Vandam, L.D. Introduction to anaesthesia, 4th edition. Philadelphia, W.B. Saunders Co. (1972).

19. Bromage, R., Robson, J. Concentrations of lignocaine in the blood after intravenous, intramuscular, epidural and endotracheal administration. Anaesthesia. 16: 461 (1961).

20. Steinhaus, J.E. \& Gaskin, L. A study of intravenous lidocaine as suppressant of cough reflex. Anesthesiology 24: 285 (1963).

21. Telrvuo, L. An experimental study on the absorption of some local anaesthetics through the lower respiratory tract. Acta Anaesthesiologica Scan., Supp. 16: 121 (1965).

22. Pelton, D.A., Dalx, M., Cooper, P.D., \& Conn, A.W. Lidocaine: concentrations in plasma following aerosol application to trachea and bronchi. Canad. Anaesthetists' Society J. 17:250(1970).

23. Glanelly, R., Von Der Groeben, J.U., Spivack, A., \& Harmison, D.C. Effect of lidocaine on ventricular arrhythmias in patients with coronary heart disease. New Engl. J. of Medicine 277: 1215 (1967).

24. Tomoni, Z. \& WindсомвE, J.G. Muscular and cardiovascular reflexes elicited by mechanical stimulation of the respiratory tract. J. Physiol. 200: 25 (1969).

25. Corbetr, J.L., Kerr, J.H. \& Prys-Roberts, C. Cardiovascular responses to aspiration of secretions from the respiratory tract in man. J. Physiol. $201: 511$ (1969). 